\title{
Therapeutic Importance of Secondary Metabolites of Extremophilic Bacteria
}

\author{
Purshottam Ojha, Shreenath Nayak and Ashok Kumar Patra* \\ Imgenex India Private Limited, India
}

Submission: March 15, 2019; Published: April 23, 2019

*Corresponding author: Ashok Kumar Patra, Imgenex India Private Limited, E5, Infocity, KIIT Post Office, Bhubaneswar, Odisha, PIN-751024,

Keywords: Biochemical compounds; Therapeutic; Bactericidal properties; Colicins; Microcins; Pyocins; Pediocins; Nisins

\section{Short Communication}

It is an established fact that microbes are a significant reservoir of biochemical compounds those have been indicated in pharmacological, physiological, medicinal or agricultural uses. These compounds may be produced due to external stimuli which could be extreme in nature such as high pressure [1], temperature, high salt and nutrition depleted condition like marine environment [2] and in most cases as the host defence mechanism. Of late, these metabolites became important to human health due to their therapeutic and bactericidal properties. There are several types of secondary metabolites are being produced by different bacterial species, for example; secretion from acidophilic bacteria help to neutralize the $\mathrm{pH}$ of certain cytoplasmic membranes [3]; biosurfactants produced by some marine bacteria increases the bioavailability by transporting hydrophobic low water-soluble substrates. Siderophores secreted by bacteria helps in iron ion transport and bioavailability. Bacteria are also known to produce molecules that prevent the attachment, growth and/or survival of challenging organisms in competitive environments. Similarly, enzymes from thermophilic bacteria have been known to help in DNA processing, production of proteins and other biotechnological processes (Oost 1996). Among the bacteria there are some extremophiles which are radiation-resistant, and their secreted products are implicated for developing anticancer drugs, antioxidants, and sunscreens $[4,5]$. Under extreme conditions like high pressure, temperature and salinity, bacteria exhibit adaptive changes which reflect in their extracellular lipid composition, hapanoids and pentacyclic triterpenoid like compound production. Nonetheless, bacteria species under competitive environment evolve to adapt and develop their own defence system to protect themselves.

To do so, the bacteria produce anti-microbial peptides. Some of the antimicrobial peptides produce by bacteria are colicins, microcins, pyocins, pediocins, nisins etc. Besides microbes, high er order organisms also produce antimicrobial peptides (AMPs) that are essential components of innate immunity and have been shown to demonstrate antimicrobial, anti-attachment and antibiofilm properties. Due to growing evidence in support of AMPs being used as therapeutic application, specificity towards antibacterial activity, small size, amphipathic nature and net positive charge, these molecules have been rigorously researched by the scientists.

In general AMPs are made up of 10-50 amino-acid residues and are divided based on the composition of their amino acids, size and conformational structures. Structurally, AMPs can be classified in four major classes: beta-sheet, alpha-helical, loop and extended peptides. They are evolutionary conserved and produced by all life forms [6]. In higher organisms, AMPs constitute important components of the innate immunity, whereas, bacteria produce AMPs for competitional survivability for the same ecological niche [7].

Antimicrobial peptides (AMPs) also known as bacteriocins have been classified in three major categories based on their structural and physico-chemical properties [8]. Among them class III AMPs are structurally bigger and sequentially longer than other AMPs, with Colicin from E. coli having $10 \mathrm{kDa}$ molecular weight to smegmatocin from M. smegmatis having molecular weight of $75 \mathrm{kDa}$. These AMPs have well established property of anti-cancer activity [9-13].

We recently have isolated AMP from thermophilic bacteria of Bacillus sp. That shows in vitro cytotoxic activity against, MCF7 and BT474 cells while leaving intact noncancerous immortalized cells like HEK293 and HepG2 (manuscript under preparation). This is an indication that thermophilic bacteria are also a good source of AMPs that can be used for therapeutic use. Selective anti-cancer activity of AMPs from various sources are well stud- 
ied and well established in in vitro conditions, however, there is no report of successful trial in the animal model. The mode of action of AMPs is through induction of necrosis/apoptosis as a result of cell membrane permeability change. Permeability change occurs due to interaction of AMPs that have higher number of positively charged amino acids, their hydrophobicity and ability to oligomerize easily with eukaryotic cancer cells which have highly negatively charged cell surface [14].

AMPs being small molecules are mostly non-immunogenic, however, come with an inherent drawback of being easily biodegradable [15]. Hence, it is major challenge for the researcher to make them more stable and increase their systemic bioavailability to become a therapeutic drug. Efforts have been made to chemically synthesize AMP peptides and by doing site directed mutagenesis to introduce non-cleaving sites yielded not much of success [16]. However, similar studies are warranted to ensure enhancing the stability and potency of anticancer AMPs. Another hurdle in the commercialisation of therapeutic AMPs is the production and purification from natural sources on a large scale. The number of AMPs secreted by the host is very low which further reduced when a combination different chromatographic steps used in the downstream resulting in few milligrams per litre of culture supernatant [17]. Such a bottleneck can be overcome by usage of the knowledge about the genetic organization and heterologous production in different hosts system as fusion proteins. With latest development on the genetic engineering, the stage is now set where the potential of AMPs as anticancer agents should be harnessed for designing safer and better therapies for the mankind.

\section{References}

1. Delong EF, Yayanos AA (1987) Properties of the glucose-transport system in some deep-sea bacteria. Appl. Environ. Microbiol 53(3): 527-532.

2. Wai SN, Mizunoe Y, Yoshida S (1999) How Vibrio cholerae survive during starvation. FEMS Microbiol Lett 180(2): 123-131.

3. Edwards KJ, Bond PL, Gihring TM, Banfield JF (2000) An archaeal ironoxidizing extreme acidophile important in acid mine drainage. Science 287(5459): 1796-1799.
4. Singh OV, Gabani P (2011) Extremophiles: radiation resistance microbial reserves and therapeutic implications. J Appl Microbiol 110(4): 851-861.

5. Gabani P, Singh OV (2013) Radiation-resistant extremophiles and their potential in biotechnology and therapeutics, Appl Microbiol Biotechnol 97(3): 993-1004.

6. Hancock RE, Diamond G (2000) The role of cationic antimicrobial peptides in innate host defences. Trends Microbiol 8(9): 402-410.

7. Hassan M, Kjos M, Nes IF, Diep DB, Lotfipour F (2012) Natural antimicrobial peptides from bacteria: characteristics and potential applications to fight against antibiotic resistance. J Appl Microbiol 113(4): 723-736.

8. Zacharof MP, Lovitt RW (2012) Bacteriocins produced by lactic acid bacteria. APCBEE Procedia 2: 50-56.

9. Fuska J, Fuskova A, Smarda J, Mach J (1978) Effect of colicinE3 on leukemia cells P388 invitro. Experientia 35: 406-407.

10. Smarda J, Oravec C (1989) Cytocidal effect of bacteriocin on lymphoma cells. Akt Klin Onkol 21: 209-212.

11. Saito H, Watanabe T (1979) Effect of a bacteriocin produced by Mycobacterium smegmatis on growth of cultured tumor and normal cells. Cancer Res 39(12): 5114-5117.

12. Saito H, Watanabe T, Tomioka H (1979) Purification, properties and cytotoxic effect of a bacteriocin from Mycobacterium smegmatis. Antimicrob Agents Chemother 15(4): 504-509.

13. Saito H, Watanabe T (1981) Effects of a bacteriocin from Mycobacterium smegmatis on BALB/3T3 and Simian Virus 40-Transformed BALB/ cmouse cells. Microbiol Immunol 25(1): 13-22.

14. Zhao H, Sood R, Jutila A, Bose S, Fimland G, et al. (2006) Interaction of the antimicrobial peptide pheromone plantaricin A with model membranes: implications for a novel mechanism of action. Biochim Biophys Acta 1758(9): 1461-1474.

15. Bhunia AK, Johnson MC, Ray B, Belden EL (1990) Antigenic property of pediocin AcH produced by Pediococcus acidilactici H. J Appl Bacteriol 69(2): 211-215.

16. Oppegård C, Rogne P, Kristiansen PE, Nissen-Meyer J (2010) Structure analysis of the two-peptide bacteriocin lactococcin $\mathrm{G}$ by introducing D-amino acid residues. Microbiology 156(Pt 6): 1883-1889.

17. Carolissen-Mackay V, Arendse G, Hastings JW (1997) Purification of bacteriocins of lactic acid bacteria: problems and pointers. Int J Food Microbiol 34(1): 1-16.

\section{Your next submission with Juniper Publishers} will reach you the below assets 